\title{
Determination of essential and non-essential elements in Xylanthemum macropodum of Balochistan, Pakistan
}

\author{
Maria Bibi, Samiullah Khan, Attiq-Ur-Rehman Kakar, Naqeebullah Khan, Abdul Hakeem Tareen, \\ Sahifa Bibi and Habiba Taj \\ Department of Chemistry, Faculty of Basic Sciences, University of Balochistan, 87300, Quetta, Pakistan
}

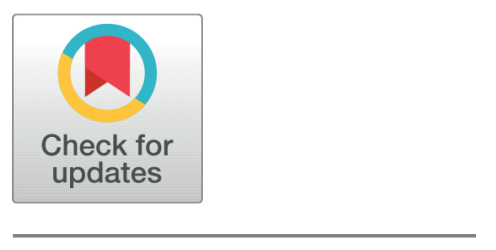

Received 02-04-2021

Revised 23-04-2021

Accepted 25-05-2021

Published 30-06-2021

\section{Corresponding Author}

Samiullah Khan

sami435889@yahoo.com;

samiullah@um.uob.edu.pk

Department of Chemistry, Faculty of Basic Sciences, University of Balochistan, Quetta 87300,

Pakistan

DOI https://doi.org/10.47419/ bjbabs.v2i02.39

Pages: 95-105

Distributed under the terms of the Creative Commons

Attribution-NonCommercial 4.0 International (CC-BY-NC 4.0), which permits use for any non-commercial purpose, distribution, and reproduction in any medium, provided that the original work is properly cited.

Copyright: (C) 2021 Maria Bibi, Samiullah Khan,

Attiq-Ur-Rehman Kakar,

Naqeebullah Khan, Abdul

Hakeem Tareen, Sahifa Bibi,

Habiba Taj

\section{ABSTRACT}

Background: Medicinal plants have been used to treat various diseases for several years throughout the world. Xylanthemum macropodum is a medicinal plant with a vast application as a home remedy in Balochistan.

Objective: The current study was conducted to determine the levels of essential and non-essential elements in Xylanthemum macropodum collected from Quetta

(Balochistan, Pakistan).

Methods: Analysis was conducted for eleven elements by using atomic absorption spectrophotometer and flame photometer.

Results: The essential and non-essential elements that were detected in Xylanthemum macropodum are $\mathrm{K}, \mathrm{Na}, \mathrm{Ca}, \mathrm{Fe}, \mathrm{Cu}, \mathrm{Co}, \mathrm{Ni}, \mathrm{Mn}, \mathrm{Cr}, \mathrm{Cd}$ and $\mathrm{Pb}$, respectively. The result of the concentration of determined elements are in the order of $\mathrm{K}>\mathrm{Na}>\mathrm{Ca}>\mathrm{Fe}>\mathrm{Cu}>\mathrm{Co}>\mathrm{Ni}>\mathrm{Mn}>\mathrm{Cd}>\mathrm{Cr}>\mathrm{Pb}$ in Xylanthemum macropodum $3000>1600>790.25>92.36>85.31>49.24>40.94>20.94>6.655>1.61>1.18 \mu \mathrm{g} / \mathrm{g}$ respectively.

Conclusions: $\mathrm{Mn}, \mathrm{Na}$ and $\mathrm{Pb}$ were found within the permissible limit given by World Health Organization, while $\mathrm{Ca}, \mathrm{Cu}, \mathrm{Fe}, \mathrm{Ni}, \mathrm{Cd}$ and $\mathrm{Cr}$ were beyond the permissible limits. However, there is no permissible limit for $\mathrm{K}$ and Co.

Keywords AAS, flame photometer, heavy metals, Xylanthemum macropodum

\section{INTRODUCTION}

The uncontrolled and rapid industrialization and urbanization of developing countries have elevated the contamination levels in the ecosystem. Various sources can participate in the contamination of the environment such as; industries, solid waste dumpsites, automobile exhaust, municipal waste management and agricultural activities. Circulation and migration of toxic metals in the environment include various processes like; volcanic eruption, sedimentary, rock decay, forest fires and evaporation of oceans. ${ }^{1}$ Despite their therapeutic effects, medicinal plants may also have adverse effects on human health, such

\section{OPEN ACCESS}


as hypertension, depression, headache, skin eruption, intestinal ulcer, anaemia, alopecia, hypoglycemia, and abdominal pain due to the presence of heavy metals. Therefore, it is essential to monitor the amount of such elements when used in medication. ${ }^{2}$

Since the beginning of human civilization, medicinal plants are used by local people to cure various diseases like; fever, hepatitis, typhoid, asthma, bronchitis, cough, diarrhoea, urinary tract infections, constipation, ulcers, pain, scrofula, kidney troubles, nervous system, immune system and heart diseases. ${ }^{3}$ Plants play an essential role in transferring elements from the biotic to the abiotic environment. They absorb metals by roots from growth media (water, soil and air) and accumulate them in various parts. Plants' ability to accumulate heavy metals depends upon various levels of organization: cell, tissue and organ. ${ }^{4}$

From the past decade's humankind have shown interest in the power and potential of medicinal plants. ${ }^{5}$ Several countries such as; Pakistan (Herbal Medicines), India (Ayurvedic Medicine), China (Traditional Chinese Medicine), Japan (Kampo Medicine), Sri Lanka, Africa, South Asia, America, France, Arabs, Ireland, England, and Germany; use medicinal plants for the cure of various illness since from ancient era. ${ }^{6}$ In the world, 2,50,000 plant species are discovered, of which 80,000 species are known for medicinal properties. As described by World Health Organization (WHO), $80 \%$ of the human's population depends upon medicinal plants for their primary health care, and $40 \%$ of pharmacological industries synthesize drugs from medicinal plants. ${ }^{7}$

Pakistan shares rich flora of 5700 plants due to its unique climate, nine major ecological zones, many topographical regions and agricultural soil. Among these, 2000 plants are medicinally important. About $80 \%$ of the local people of Pakistan rely upon herbal medicines, while $90 \%$ of medicinal plants are imported. ${ }^{8}$ However, the trade digits of medicinal plants are low than neighbouring countries such as China and India. Therefore, there is a dire need for Pakistan to develop more pharmacological industries to utilize herbal plants. Less developed areas of Pakistan such as Balochistan, Gilgit Baltistan and FATA are well-known for their biodiversity. And, the local government of these areas should participate in the development of pharmacological industries, and the therapeutic knowledge of local people must be utilized. ${ }^{9}$

Due to limited reports about the levels of essential and non-essential elements in Xylanthemum macropodum, we sought to investigate the concentrations of some of these elements in Xylanthemum macropodum collected from Quetta (Balochistan, Pakistan).

\section{MATERIALS AND METHODS Chemicals and reagents}

All the standards and reagents were of analytical grade. The mixture of concentrated Nitric Acid $\left(\mathrm{HNO}_{3}\right)$, Sulphuric Acid $\left(\mathrm{H}_{2} \mathrm{SO}_{4}\right)$ and Per Chloric Acid $\left(\mathrm{HClO}_{4}\right)$ was used for digestion purpose. Merck KgaA, Damnstadt, manufactured the reagents used. For calibration purposes, $1000 \mathrm{ppm}$ stock solution (Merck) of various metals $(\mathrm{Ca}, \mathrm{Cd}, \mathrm{Co}, \mathrm{Cr}, \mathrm{Cu}$, $\mathrm{Fe}, \mathrm{K}, \mathrm{Mn}, \mathrm{Na}, \mathrm{Ni}, \mathrm{Pb}$ ) were used, and distilled water was utilized dilution of samples and 
standards.

\section{Instrumentation}

Flame atomic absorption spectroscopy (FAAS) model S4 AA (Thermo) was used for the analysis of $\mathrm{Cu}, \mathrm{Cd}, \mathrm{Co}, \mathrm{Pb}, \mathrm{Fe}, \mathrm{Ni} \cdot \mathrm{Mn}$ (Atomize in the presence of Acetylene gas) and $\mathrm{Ca}, \mathrm{Cr}$ (Atomize in the presence of Acetylene and Nitrous gases). FAAS is an analytical technique used for the quantification of 70 elements. Atomic Absorption Spectroscopy is the most suitable technique as it is highly sensitive, low detection limit, low cost and easy to operate. ${ }^{10}$ AAS works on a principle of absorption of electromagnetic radiation (EMR) by the vaporized atom of the specific element. For the analysis purpose, the solution was aspirated into flame, then the vaporized atoms absorbed at a specific wavelength and the degree of absorbed radiation was measured.

Flame photometer model PFP7 (Jenway) was used for the analysis of $\mathrm{K}$ and Na. Flame atomic emission spectroscopy (FAES) is a quantitative analytical technique used to determine alkali and alkaline earth metals. ${ }^{11}$ It is the most suitable and low-cost technique for the analysis of sodium and potassium. It works on the principle of emission of radiation by vaporized excited atom. For the analysis purpose, the sample is aspirated into flame then the vaporized atoms absorb thermal energy and become excited. The excited atoms emit radiation of a specific wavelength, and the degree of emitted radiation is measured.

\section{Sample collection and sample preparation}

The selected medicinal plant Xylanthemum macropodum (Figure 1) was collected from Hanna valley, North of Quetta, Balochistan (Figure 2). The collected plant sample was brought to the laboratory of the Department of Chemistry, University of Balochistan in Quetta and then, it was washed with ultra-pure deionized water and dried carefully without exposure to direct sunlight. Finally, the dried plant sample was ground in an electric grinder to obtain fine powder for further analysis.

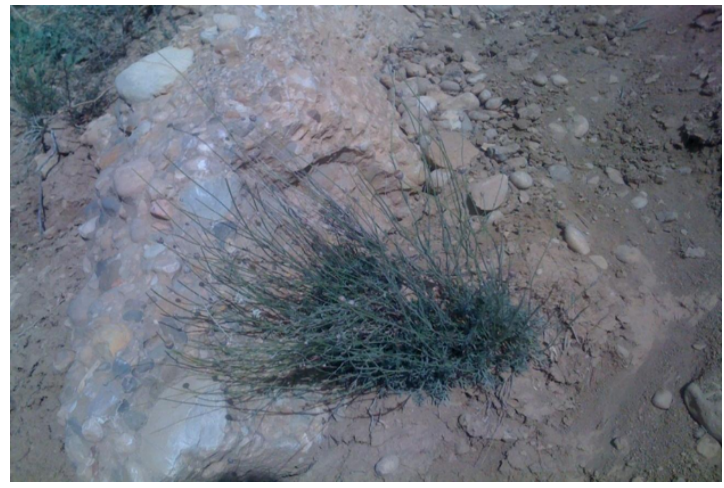

Figure 1 Xylanthemum macropodum plant. 


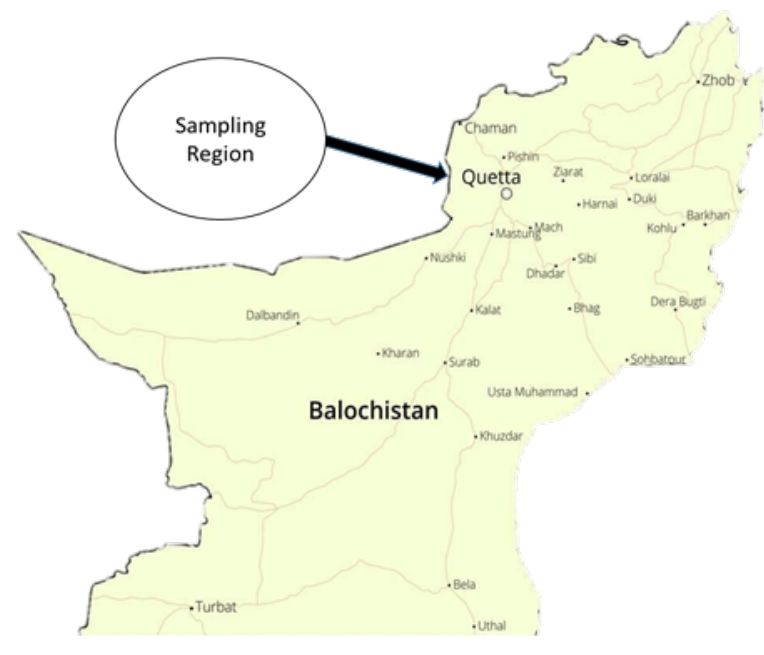

Figure 2 Map of Balochistan.

\section{Acid digestion}

One gram of powdered Xylanthemum macropodum plant sample was weighed and taken in a $50 \mathrm{ml}$ Erlenmeyer flask, and the mixture of three acids $\left(\mathrm{HNO}_{3}, \mathrm{H}_{2} \mathrm{SO}_{4}, \mathrm{HClO}_{4}\right)$ was used in the ratio of 10:2:1 for digestion. The prepared mixture of the plant was heated on an electric hot plate at $80-85^{\circ} \mathrm{C}$ in a fuming hood. The sample was heated until complete digestion is accomplished, indicated by the occurrence of white fumes. The sample was allowed to cool down at room temperature and then was transferred to a $50 \mathrm{~mL}$ volumetric flask and was diluted by distilled water up to the mark. Then, the diluted sample was filtered by Whatman No. 42 filter paper and further used for elemental analysis. ${ }^{12}$

\section{Blank and standards}

A $0.5 \mathrm{M}$ blank of $\mathrm{HNO}_{3}$ was prepared for the dilution of standards of various concentrations. By utilizing $1000 \mathrm{ppm}$, stock solution of various metals five standards of various concentration of each metal was prepared for calibration of the instrument. After calibration of the instrument, the sample was aspirated into flame to analyse various metals, and the obtained data was interpreted.

\section{RESULTS AND DISCUSSION}

Medicinal plants may be contaminated with heavy metals due to various environmental processes that occur during the plant's growth. It is necessary to determine essential and non-essential metals in plants to protect humans from the toxic effects of non-essential metals and determine the nutritional value of medicinal plants. ${ }^{3}$ In the present study, the con- 
centration of eleven metals was analyzed utilizing FAAS and FAES in Xylanthemum macropodum. The concentrations order of the eleven metals (K, Na, Ca, Fe, Cu, Co, Ni, Mn, Cd, Cr, $\mathrm{Pb}$ ) in Xylanthemum macropodum were 3000, 1600, 790.25, 92.36, 85.31, 49.24, 40.94, 20.94, $6.655,1.61,1.18 \mu \mathrm{g} / \mathrm{g}$ respectively (Table 1 ). Consequently, the comparison of the concentration of these metals is accomplished by plotting a graph shown in. The concentration of eleven metals in Xylanthemum macropodum is compared with the maximum permissible limits (MPL) of metals in medicinal plants set by the World Health Organization (Table 2). Their impacts on human health are also discussed.

Table 1 The concentration of elements in Xylanthemum macropodum $(\mu \mathrm{g} / \mathrm{g})$.

\begin{tabular}{lllllllllll} 
Ca & Cd & Cr & Co & Cu & Fe & Pb & Mn & Ni & K & Na \\
790.25 & 6.655 & 1.61 & 49.24 & 85.31 & 92.36 & 1.18 & 20.94 & 40.94 & 3000 & 1600 \\
\hline
\end{tabular}

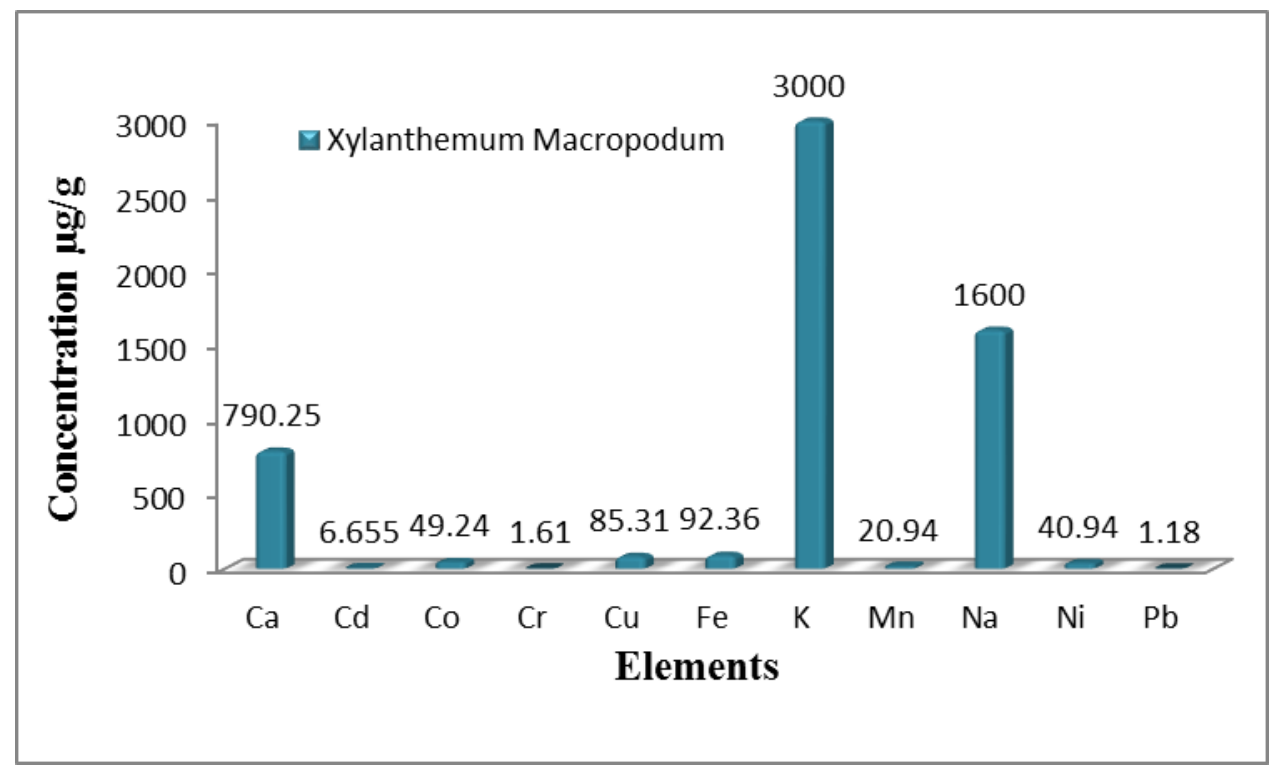

Figure 3 Comparison of concentration of various metals in Xylanthemum macropodum.

\section{Determination of essential metals Calcium (Ca)}

Calcium is one of the most essential and abundant elements in the human body. It plays various roles in the human body, such as building strong bones \& teeth, absorption of vitamin B, preventing osteoporosis, releasing hormones, activating enzymes, and contraction of muscles. Its deficiency results in weakness of bones and abnormality in heartbeats which may lead to a heart attack. Recommended Dietary Allowance (RDA) for Ca is 500-1000 $\mathrm{mg} /$ day for children and $800 \mathrm{mg} /$ day for adults. MPL of Ca for the medicinal plant is 614 
ppm. ${ }^{13}$ The concentration of Ca in Xylanthemum macropodum is $790.25 \mu \mathrm{g} / \mathrm{g}$, and it is concluded that the concentration of calcium was higher than the permissible limit.

\section{Chromium (Cr)}

Cr is the $7^{\text {th }}$ most abundant element. Chromium is a trace element in the human body. It has essential functions in carbohydrate metabolism, cholesterol synthesis from acetate in the liver, stimulation of fatty acid, and improved sugar metabolism. Cr deficiency causes an increase in haematological parameters. RDA for Cr is $35 \mathrm{mg} /$ day for men and $25 \mathrm{mg} /$ day for female. ${ }^{14} \mathrm{MPL}$ of $\mathrm{Cr}$ for edible plants is $0.02 \mathrm{ppm}$ ((Food and Agricultural Organization) FAO/WHO, 1984), and for the medicinal plant is $1.5 \mathrm{mg} / \mathrm{kg}$ (WHO). The concentration of $\mathrm{Cr}$ in Xylanthemum macropodum is $1.61 \mu \mathrm{g} / \mathrm{g}$, and it was concluded that chromium was in a higher concentration than the permissible limit.

\section{Cobalt (Co)}

Co is a naturally occurring metal in the earth crust. ${ }^{5}$ Cobalt is an essential trace element for the human body and is an essential component of vitamin $\mathrm{B}_{12}$, a high intake of cobalt results in heart diseases. At the same time, its deficiency results in anaemia and hypothyroidism. The RDA for Co is 5-40 $\mu \mathrm{g} /$ day. No MPL are determined for Cobalt in medicinal plants. ${ }^{13}$ The concentration of Co in Xylanthemum macropodum was $49.24 \mu \mathrm{g} / \mathrm{g}$.

\section{Copper (Cu)}

$\mathrm{Cu}$ is the third most abundant (150mg) trace element found in the human body. High intake of $\mathrm{Cu}$ has adverse effects on human health like; liver toxicity, kidney damage, nausea, anaemia and cancer (Group D carcinogenic). ${ }^{8}$ At the same time, its deficiency results in cardiovascular diseases. RDA for $\mathrm{Cu}$ is $2-5 \mathrm{mg} /$ day. MPL of $\mathrm{Cu}$ for edible plants is $3.00 \mathrm{ppm}$ (FAO/WHO26, 1984) and for the medicinal plant is $10 \mathrm{mg} / \mathrm{kg}$ (WHO). ${ }^{14}$ The concentration of $\mathrm{Cu}$ in Xylanthemum macropodum is $85.31 \mu \mathrm{g} / \mathrm{g}$, and it was concluded that copper was in a higher concentration than the permissible limit.

\section{Iron (Fe)}

Fe is an essential element for all living organisms and the second most abundant element on earth crust. Iron is the most abundant metal (3-4 g) and is considered an essential element for the human body. In humans, it is the main component of several enzymes, haemoglobin and myoglobin. In comparison, Iron deficiency results in anaemia. RDA for Fe is $8 \mathrm{mg} /$ day for males and $18 \mathrm{mg} /$ day for females. MPL of Fe for edible plants is $20 \mathrm{ppm}$ (FAO/WHO, 1984), and for the medicinal plant is $15 \mathrm{mg} / \mathrm{kg}$ (WHO). ${ }^{13}$ Therefore, the con- 
centration of Fe in Xylanthemum macropodum is $92.36 \mu \mathrm{g} / \mathrm{g}$, and it was concluded that iron was in a higher concentration than the permissible limit.

\begin{tabular}{|c|c|c|c|}
\hline \multirow[t]{2}{*}{ Elements } & \multirow[t]{2}{*}{ RDA (mg/day) } & \multicolumn{2}{|l|}{ WHO's MPL } \\
\hline & & Medicinal plants (mg/kg) & Edible plants (ppm) \\
\hline Calcium & $\begin{array}{l}500-1000 \\
\text { (adults) }\end{array}$ & 614 ppm & - \\
\hline Cadmium & - & 0.3 & $0.2-0.81$ \\
\hline Chromium & 35 (males) 25 (females) & 1.5 & 0.02 \\
\hline Cobalt & $5-40 \mu \mathrm{g} /$ day & - & - \\
\hline Copper & $2-5$ & 10 & 3 \\
\hline Iron & 8 (males) 18 (females) & 15 & 20 \\
\hline Lead & - & 10 & 0.43 \\
\hline Manganese & 2.3 (males) 1.8 (females) & 200 & 2 \\
\hline Nickel & $80-130 \mu \mathrm{g} /$ day & 1.5 & 1.63 \\
\hline Potassium & 2300 & - & - \\
\hline Sodium & $1-3.8$ & 51340 & - \\
\hline
\end{tabular}

\section{Manganese (Mn)}

On the earth crust, $\mathrm{Mn}$ is the $12^{\text {th }}$ most abundant element (average concentration $0.1 \%$ ). It is a trace element $(12 \mathrm{mg})$ found in the human body and it is one of the essential nutrients for human health. High intake of Mn can result in neurological disorders. While its deficiency results in dermatitis, deafness, changes in hair color, hypercholesterolemia, infertility, impaired glucose tolerance and skeletal abnormalities. RDA for Mn is $2.3 \mathrm{mg} / \mathrm{day}$ for men and $1.8 \mathrm{mg} /$ day for women. MPL of Mn for edible plants is $2.00 \mathrm{ppm}(\mathrm{FAO}, 1984)$ and for the medicinal plant is $200 \mathrm{mg} / \mathrm{kg}$ (WHO). ${ }^{13}$ The concentration of Mn in Xylanthemum macropodum was $20.94 \mu \mathrm{g} / \mathrm{g}$, and it was concluded that manganese was within the range of MPL.

\section{Nickel (Ni)}

Nickel is a transition metal that is naturally found in the environment. It is essential in trace amounts while high $\mathrm{Ni}$ intake has adverse effects on human health such as; sickness and dizziness, respiratory diseases, asthma and chronic bronchitis, lung cancer, larynx cancer, nose cancer, prostate cancer, birth defects, and birth defects, allergic reactions and heart disorders. ${ }^{15} \mathrm{RDA}$ for $\mathrm{Ni}$ is $80-130 \mu \mathrm{g} /$ day. MPL of $\mathrm{Ni}$ for edible plants is $1.63 \mathrm{ppm}$ (FAO/WHO, 1984), and for the medicinal plant is $1.5 \mathrm{mg} / \mathrm{kg}$ (WHO). ${ }^{13}$ Therefore, the concentration of $\mathrm{Ni}$ in Xylanthemum macropodum was $40.94 \mu \mathrm{g} / \mathrm{g}$, and it was concluded that nickel was in a higher concentration than the permissible limit. 


\section{Potassium (K)}

Potassium is one of the richest element in living organisms. It plays a vital role in the maintenance of cell function such as nerve and muscle cells. Potassium is beneficial for reducing blood pressure, improve glucose control and insulin resistance. The RDA for K is $2300 \mathrm{mg}$ /day. The concentration of $\mathrm{K}$ in Xylanthemum macropodum was $3000 \mu \mathrm{g} / \mathrm{g} .{ }^{9}$

\section{Sodium (Na)}

Sodium is one of the essential and richest elements in the human body. It is essential for the maintenance of physiology and optimal growth of the human body. A high concentration of $\mathrm{Na}$ results in hypertension. At the same time, its deficiency causes fatigue, mode change, hair loss, muscle cramps, dehydration and hypotension. RDA for $\mathrm{Na}$ is 1-3.8 g/day. MPL of Na for the medicinal plant is $51340 \mathrm{ppm}^{7}$ The concentration of $\mathrm{Na}$ in Xylanthemum macropodum was $1600 \mu \mathrm{g} / \mathrm{g}$, and it was concluded that sodium was within the range of MPL.

\section{Determination of non-essential metals Cadmium (Cd)}

Cadmium is the $7^{\text {th }}$ toxic heavy element on earth (ATSDR), and it has adverse effects on human health. In humans, it causes high blood pressure damages the kidney and liver. ${ }^{16}$ The MPL of Cd for edible plants is 0.2 to $0.81 \mathrm{ppm}$ (WHO22) and for the medicinal plant is $0.3 \mathrm{mg} / \mathrm{kg}$ (WHO). ${ }^{12}$ The concentration of Cd in Xylanthemum macropodum was 6.655 $\mu \mathrm{g} / \mathrm{g}$, and it was concluded that $\mathrm{Cd}$ was in a higher concentration than the permissible limit.

\section{Lead (Pb)}

Lead is a highly toxic metal. Industrial processes, storage batteries, food and smoking, gasoline and house paint, drinking water and domestic sources are causes of lead contamination in the environment. There is no biological role of lead in the human body. However, lead harms human health, and high concentration can damage the kidney, brain, reproductive system, nervous system and cause high blood pressure. ${ }^{17}$ The MPL of $\mathrm{Pb}$ for edible plants is $0.43 \mathrm{ppm}$ (FAO/WHO, 1984), and for the medicinal plant is $10 \mathrm{mg} / \mathrm{kg}$ (WHO). ${ }^{13}$ The concentration of $\mathrm{Pb}$ in Xylanthemum macropodum was $1.18 \mu \mathrm{g} / \mathrm{g}$, and it was concluded that lead was within the range of MPL.

\section{CONCLUSIONS}


The present study shows that the concentration of detected metals in Xylanthemum macropodum was within the range of acceptable value fixed by FAO/WHO. The concentration of both essential and non-essential elements was determined. The concentration of calcium, iron, potassium and sodium were found higher among the assessed metals. These metals are beneficial for human health. However, other elements were within the range of permissible limit by FAO/WHO. Thus, the plant Xylanthemum macropodum has non-toxic effects on human health and safe to use as a drug. Nonetheless, the plant must be monitored before using it as medicine because several environmental factors can cause contamination of medicinal plants.

\section{ACKNOWLEDGEMENTS}

The authors are thankful to the Department of Chemistry, University of Balochistan, Quetta, for providing us facilities to accomplish the present work.

\section{DECLARATIONS}

\section{Authors' contributions}

AK, NK, AT, SB and HT contributed to the practical part of this work. MB wrote the original draft. SK supervised the project. All authors reviewed and approved this paper before publication.

\section{Conflict of interest}

The authors declare that there is no conflict of interest.

\section{Ethical approvals}

This work was done and approved by the Department of Chemistry, University of Balochistan, Quetta in November 2020.

\section{Data availability}

The data associated with this work can be requested from the corresponding author.

\section{Funding resources}

This work did't receive any fund.

\section{REFERENCES}

1. Wu Q, Leung JY, Geng X, Chen S, Huang X, Li H, et al. Heavy metal contamination of soil and water in the vicinity of an abandoned e-waste recycling site: implications for dissemination of heavy metals. Sci Total Environ. 2015;506:217-225. Available from: 10.1016/j.scitotenv.2014.10.121. 
2. Dogan Y. A study on detecting heavy metal accumulation through biomonitoring: content of trace elements in plants at Mount Kazdagi in Turkey. Appl Ecol Environ Sci Res. 2014;12(3):627-636. Available from: 10.15666/aeer/1203_627636.

3. Vaikosen EN, Alade GO. Determination of heavy metals in medicinal plants from the wild and cultivated garden in Wilberforce Island, Niger Delta region, Nigeria. J Pharm Pharmacogn Res. 2017;5(2):129-143.

4. Stanojkovic-Sebic A, Pivic R, Josic D, Dinic Z, Stanojkovic A. Heavy metals content in selected medicinal plants commonly used as components for herbal formulations. J Agric Sci. 2015;21(3):317-325. Available from: 10.1501/tarimbil_0000001334.

5. Helaluddin ABM, Khalid RS, Alaama M, Abbas SA. Main Analytical Techniques Used for Elemental Analysis in Various Matrices. Trop J Pharm Res. 2016;15(2):427434. Available from: 10.4314/tjpr.v15i2.29.

6. Şahin I, Akcicek E, Güner Ö, Doğan Y, Uğulu İ. An investigation on determining heavy metal accumulation in plants growing at Kumalar Mountain in Turkey. Eurasia J Biosci. 2016;10:22-29. Available from: 10.5053/ejobios.2016.10.0.3.

7. Bobaker AM, Alakili I, Sarmani SB, Al-Ansari N, Yaseen ZM. Determination and Assessment of the Toxic Heavy Metal Elements Abstracted from the Traditional Plant Cosmetics and Medical Remedies: Case Study of Libya. Int J Environ Res Public Health. 2019;16(11):1957-1957. Available from: 10.3390/ijerph16111957.

8. Maobe MA, Gatebe E, Gitu L, Rotich H. Profile of heavy metals in selected medicinal plants used for the treatment of diabetes, malaria and pneumonia in Kisii region, Southwest Kenya. Glob J Pharmacol. 2012;6(3):245-51. Available from: 10.5829/ idosi.gjp.2012.6.3.65128.

9. Caldas ED, Machado LL. Cadmium, mercury and lead in medicinal herbs in Brazil. Food Chem Toxicol. 2004;42:599-603. Available from: 10.1016/j.fct.2003.11.004.

10. Hassan W, Rehman S, Noreen H, Gul S, Kazmi SN. Metallic Content of One Hundred (100) Medicinal Plants. J Nutr Disorders Ther. 2015;5(177):245-251. Available from: 10.5829/idosi.gjp.2012.6.3.65128.

11. Afrin S, Khan MN, Haque P, Rahman MM. Determination of Serum Copper and Zinc Level of Bangladeshi Breast Cancer Patients. ARC J Cancer Sci. 2018;47:49-57. Available from: 10.20431/2455-6009.0402002.

12. Kiazai I. Determination of heavy metals concentration in Astragalus anisacanthus and Ebenus stellata of Balochistan, Pakistan. Pure Appl Biol. 2019;8(3):2028-2035. Available from: 10.19045/bspab.2019.80147.

13. Karpiuk UV, Azzam KMA, Abudayeh ZHM, Kislichenko V, Naddaf A, Cholak I, et al. Qualitative and Quantitative Content Determination of Macro-Minor Elements in Bryonia Alba L. Roots using Flame Atomic Absorption Spectroscopy Technique. Adv Pharm Bull. 2016;6(2):285-291. Available from: 10.15171/apb.2016.040.

14. Al-Fartusie FS, Mohssan SN. Essential trace elements and their vital roles in human body. Indian J Adv Chem Sci. 2017;5(3):127-136. Available from: 10.22607/IJACS. 2017.503003. 
15. Parveen R, Abbasi AM, Shaheen N, Shah MH. Accumulation of selected metals in the fruits of medicinal plants grown in urban environment of Islamabad, Pakistan. Arab J Chem. 2020;13(1):308-317. Available from: 10.1016/j.arabjc.2017.04.010.

16. Shah A, Niaz A, Ullah N, Rehman A, Akhlaq M, Zakir M, et al. Comparative Study of Heavy Metals in Soil and Selected Medicinal Plants. J Chem. 2013;2013:1-5. Available from: 10.1155/2013/621265.

17. Stone M, Martyn L, Weaver C. Potassium Intake, Bioavailability, Hypertension, and Glucose Control. Nutrients. 2016;8(7):444-444. Available from: 10.3390/ nu8070444. 